\title{
Moored Observations of Transport and Variability of Halmahera Sea Currents
}

\author{
XIANG LI \\ Key Laboratory of Ocean Circulation and Waves, Institute of Oceanology, Chinese Academy of Sciences, and \\ Qingdao National Laboratory for Marine Science and Technology, and Center for Ocean Mega-Science, \\ Chinese Academy of Sciences, Qingdao, China \\ DONGLIANG YUAN \\ Key Laboratory of Ocean Circulation and Waves, Institute of Oceanology, Chinese Academy of Sciences, and \\ Qingdao National Laboratory for Marine Science and Technology, and Center for Ocean Mega-Science, \\ Chinese Academy of Sciences, Qingdao, and University of Chinese Academy of Sciences, Beijing, China

\section{ZHENG WANG AND YAO LI} \\ Key Laboratory of Ocean Circulation and Waves, Institute of Oceanology, Chinese Academy of Sciences, and \\ Qingdao National Laboratory for Marine Science and Technology, and Center for Ocean Mega-Science, \\ Chinese Academy of Sciences, Qingdao, China
}

\section{CORRY CORVIANAWATIE}

Key Laboratory of Ocean Circulation and Waves, Institute of Oceanology, Chinese Academy of Sciences, and Qingdao National Laboratory for Marine Science and Technology, and Center for Ocean Mega-Science, Chinese Academy of Sciences, Qingdao, and University of Chinese Academy of Sciences, Beijing, China, and Research Center for Oceanography, Indonesian Institute of Sciences, Jakarta, Indonesia

\section{Dewi Surinati, Asep Sandra, Ahmad Bayhaqi, Praditya Avianto, Edi Kusmanto, DIRHAM DIRHAMSYAH, AND ZAINAL ARIFIN}

Research Center for Oceanography, Indonesian Institute of Sciences, Jakarta, Indonesia

(Manuscript received 7 May 2019, in final form 22 November 2019)

\begin{abstract}
The ocean currents in the Halmahera Sea are studied using a subsurface mooring deployed in the Jailolo Strait from November 2015 to October 2017. The subtidal currents of the mooring measurements are characterized by a two-layer system, with the current variability below about $200 \mathrm{~m}$ in opposite phases to that in the upper layer. The mean along-strait velocity (ASV) is toward the Indonesian seas in the whole water column, producing an estimated mean transport of $2.44 \pm 0.42 \mathrm{~Sv}\left(1 \mathrm{~Sv} \equiv 10^{6} \mathrm{~m}^{3} \mathrm{~s}^{-1}\right)$. The errors of the transport calculation based on the single mooring measurements are estimated to be less than $15 \%$ using simulations of high-resolution ocean models. A weak current is observed to flow northward during 2017 at the bottom of the strait. The ASV variability is found to be dominated by an annual cycle both in the upper and lower layers. The total transport, however, is dominated by semiannual variability because of the cancelation of the annual transports in the upper and lower layers. The variability of the transport is suggested to be driven by the pressure difference between the Pacific Ocean and the Indonesian seas, as evidenced by the agreement between the satellite pressure gradient and the two-layer transports. The transport of the Jailolo Strait during the 2015/16 super El Niño is found to be nearly the same as that during the 2016 La Niña, suggesting that the interannual variability of the transport is much smaller than the seasonal cycle.
\end{abstract}

\section{Introduction}

The Indonesian Throughflow (ITF) is the only tropical connection of the global oceans, which links the warm pool of the western Pacific Ocean and eastern 
Indian Ocean, and hence plays an important role in the variability of global climate. There are two major pathways of the ITF in the western and eastern Indonesian seas (Gordon 2005), and several minor pathways such as the Karimata Strait between the South China Sea and the Java Sea (Fang et al. 2010; Susanto et al. 2010). Observations show that the thermocline waters from the North Pacific Ocean enter the Makassar Strait, which is the western route of the ITF, consisting of the most transport for the ITF (Gordon et al. 1999; Susanto and Gordon 2005; Gordon et al. 2008; Susanto and Song 2015; Gordon et al. 2019). In addition, water transport through the Maluku Sea and the Halmahera Sea can contribute to the ITF, which is the eastern route of the ITF (Gordon 2005). Sporadic observations have suggested that salty lower-thermocline waters from the South Pacific Ocean enter the Halmahera Sea and meet the western route ITF in the Banda Sea (Gordon and Fine 1996; Gordon 2005).

The ITF transport have been estimated based on inverse calculation (Wunsch et al. 1983; Fu 1986; Toole and Warren 1993), the island-rule theory (Godfrey 1996), direct observations (Meyers 1996; Gordon et al. 1999; Sprintall et al. 2009; Gordon et al. 2010), and ocean model simulations (Masumoto and Yamagata 1996; Gordon and McClean 1999; Liu et al. 2005; Metzger et al. 2010). Synchronous mooring observations of ocean currents in the Makassar Strait and in the major exit channels of the ITF have been made during the International Nusantara Stratification and Transport (INSTANT) program, which give an estimated total transport of $15.0 \mathrm{~Sv}\left(1 \mathrm{~Sv}=10^{6} \mathrm{~m}^{3} \mathrm{~s}^{-1}\right)$ flowing into the Indian Ocean (Sprintall et al. 2009; Gordon et al. 2010). There is an imbalance of $\sim 2 \mathrm{~Sv}$ between the outflow transports and the inflow transports through the Makassar Strait and the Lifamatola Passage, which has been attributed in part to the transports in the Halmahera Sea (Gordon et al. 2010). The currents through the Halmahera Sea were not measured during the INSTANT program. Historically, mooring measurements were conducted during 1993-94 in the Halmahera Sea (Cresswell and Luick 2001). Because of malfunction of the upward-looking acoustic Doppler current profiler (ADCP), the currents above 400-m depth were not measured successfully. The Indonesian Mixing Program (INDOMIX) focused mainly on the thermohaline stratification and mixing processes (Koch-Larrouy et al. 2015). Thus, there is a lack of estimation of the upperthermocline transports in the Halmahera Sea based on mooring measurements to date.

The Halmahera Sea has been suggested to be the primary channel of the interbasin wave propagation between the Pacific and the Indian Oceans based on tide gauge sea level data (Clarke and Liu 1994), which was confirmed by lag correlations of the expendable bathythermograph (XBT) data (Wijffels and Meyers 2004). A waveguide is suggested that the westward-propagating Rossby waves from the equatorial Pacific Ocean excite coastally trapped waves in the Indonesian seas, which propagate toward the Indian Ocean along the west coast of the New Guinea Island and the Australian continent. However, the role of the Halmahera Sea currents in the propagation of the interannual waves into the Indonesian seas during a major El Niño event has not been examined using direct current measurements.

Starting from 2014, joint surveys of the Institute of Oceanology, Chinese Academy of Sciences (IOCAS) and the Research Center for Oceanography, Indonesian Institute of Sciences (RCO/LIPI) have been conducted annually in the eastern Indonesian seas. The cruises are supported by multiple research programs including the Chinese Academy of Sciences strategic priority project, the National Basic Research Program of China, the Pilot National Laboratory for Marine Science and Technology, and National Science Foundation of China. Up to 10 synchronous subsurface moorings with current meters and conductivity-temperature-depth (CTD) instruments were deployed in the key passages of the ITF. The results of the mooring observations in the Maluku Channel have recently been reported by Yuan et al. (2018b) and simulated by $\mathrm{Hu}$ et al. (2019). In this paper, we focus on the current measurements in the Jailolo Strait from November 2015 to October 2017 to study the transport and variability of the currents in the Halmahera Sea (Fig. 1).

The data and methods of analysis used in this study are described in section 2 . The mean vertical structure and variability of the currents in the Jailolo Strait are analyzed based on the moored current meters in section 3. Also, the transport of the Jailolo Strait is estimated using the mooring data, the dynamics of which is investigated using satellite sea level and ocean bottom pressure data. Uncertainties of the transport estimates are discussed in section 4. Conclusions are contained in section 5 .

\section{Data and method}

The Jailolo Strait mooring was first deployed at $0^{\circ} 1^{\prime} \mathrm{S}$, $129^{\circ} 5^{\prime} \mathrm{E}$ on 3 November 2015 and was rotated twice on 13 November 2016 and 11 October 2017 (Fig. 1). The mooring was located slightly south of the narrowest choke of the Jailolo Strait in the Halmahera Sea in a depth of water of $1130 \mathrm{~m}$. The Halmahera Sea topography is characterized with a deep basin of over 2000-m maximum depth. Shallow sills exist in the northern and southern Halmahera Sea facing the Pacific Ocean and the interior Indonesian seas, respectively. Both sills are 


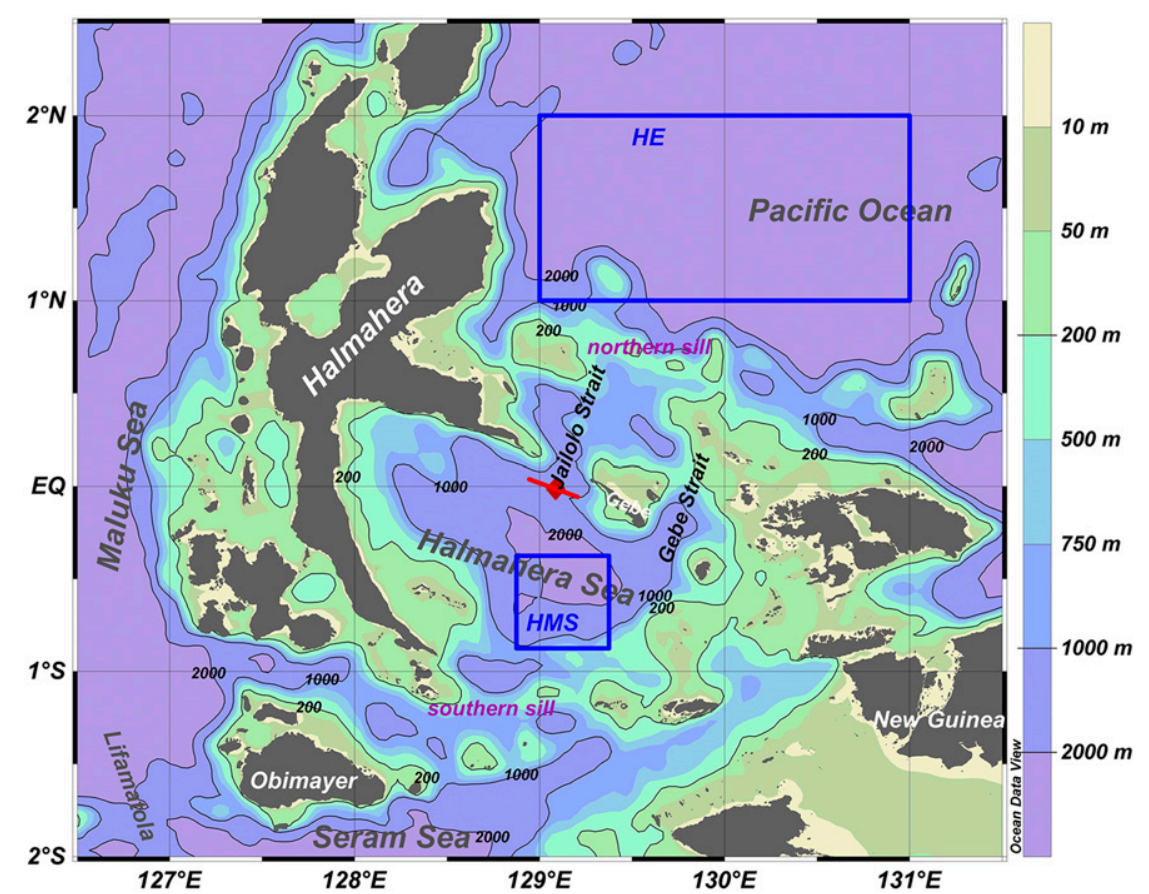

FIG. 1. Bathymetry (m) around the Halmahera Sea based on the ETOPO1 database. The red diamond indicates the mooring location in the Jailolo Strait. The red line through the mooring location represents the section used for transport calculation. Blue-outlined rectangles show the box locations for the transport estimation based on satellite pressure data.

much shallower than the depth of the mooring, although the exact depths of the sills are not accurately known. The effective sill depth of the Halmahera Sea is estimated to be $\sim 580 \mathrm{~m}$ based on historical hydrography data (Gordon et al. 2003).

All the mooring deployment and rotation cruises were conducted on board the Indonesian research vessel (R/V) Baruna Jaya VIII. In addition, hydrography profiles and upper-ocean currents were measured by the Sea-Bird 911plus CTD and the RD Instruments, Inc., 75-KHz shipboard ADCP (SADCP) during the cruises. The annual joint cruises between IOCAS and RCO/LIPI usually cover the eastern Indonesian seas including the Maluku, Halmahera, and Seram Seas, and some sections at the entrance of ITF in the western Pacific Ocean. These SADCP data are postprocessed using Common Ocean Data Access System (COADS) software (https://currents.soest.hawaii.edu/docs/adcp_doc/ index.html), including calibration and quality control. The barotropic tidal currents of four principal constituents extracted from the TPXO model, version 9 (Egbert and Erofeeva 2002), are subtracted from the postprocessed SADCP velocities, which are then smoothed with a 2 -h running mean filter to suppress the high-frequency variability. It is worth mentioning that the baroclinic tidal currents of over $15 \mathrm{~cm} \mathrm{~s}^{-1}$ in the thermocline according to the mooring measurements (figure omitted) are not removed. The potential temperature profiles of the shipboard CTD casts in the Halmahera Sea during the IOCAS-RCO/LIPI cruises show agreement of the temperature in the deep basin with the temperature of the Pacific Ocean at about $550 \mathrm{~m}$, but significantly different from the Pacific temperature at deeper depths, suggesting that the sill depth at the Pacific entrance of the Halmahera Sea is about $550 \mathrm{~m}$ (Fig. 2).

\section{a. The mooring data}

In the first deployment, two 75-KHz ADCPs manufactured by RD Instruments, Inc., looking upward and downward were mounted on the main float of the mooring at a nominal depth of $500 \mathrm{~m}$ to measure the ocean currents in the depth range of $50-970 \mathrm{~m}$. The downward-looking ADCP was replaced with two Aanderaa current meters at nominal depths of 800 and $1000 \mathrm{~m}$ in the second deployment in November 2016. The ADCPs are configured to have sixty 8-m bins with the sampling time interval at $1 \mathrm{~h}$. The Aanderaa current meters are also set to measure the currents at $1-\mathrm{h}$ intervals.

The raw data of the ADCPs are quality controlled according to the standard procedure following 


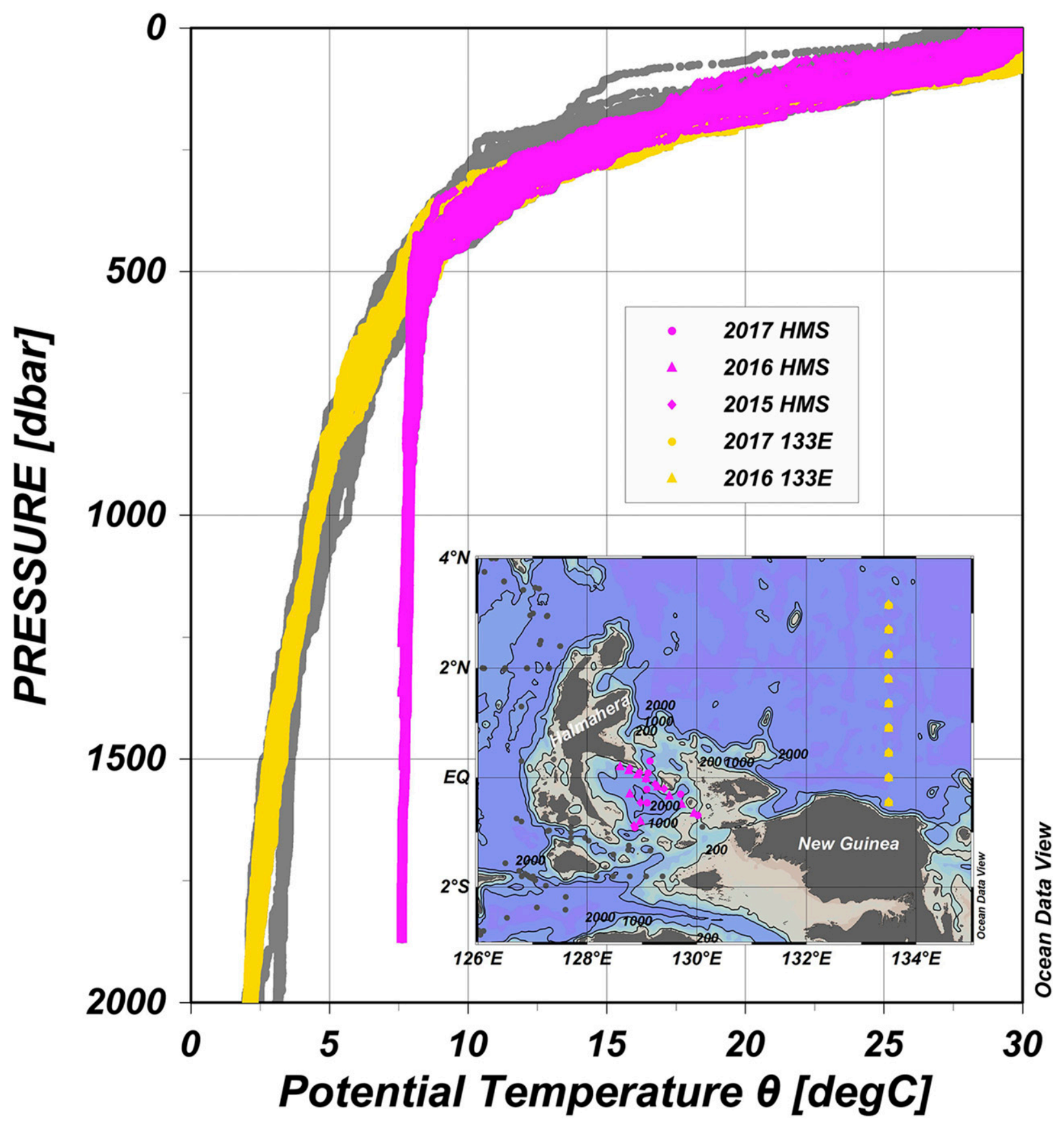

FIG. 2. Potential temperature profiles from the CTD casts during the IOCAS-RCO/LIPI joint cruises. The inset map shows depths (m). Yellow symbols show the profiles in the $133^{\circ} \mathrm{E}$ section in the western equatorial Pacific Ocean during the 2016 and 2017 cruises. Purple symbols show the profiles in the Halmahera Sea during the 2015, 2016, and 2017 cruises. Gray dots stand for the profiles at the other stations in the map during the 2014-17 cruises.

Cowley et al. (2008). Sporadic missing data are filled with linear interpolation in the vertical. The time series from different instruments are interpolated to the same integer hours. The ADCP and current-meter data are linearly interpolated onto a 1-m vertical grid according to pressure sensors of the instruments, which are then averaged into a 10-m grid for analysis. The magnitude of blow down of the main floats due to the tidal currents is usually several tens of meters within 1 day, which sometimes reaches $100 \mathrm{~m}$ during the spring-neap tides.

At the surface, the ADCP data in the top $40 \mathrm{~m}$ are contaminated by the reflection from the sea surface and 

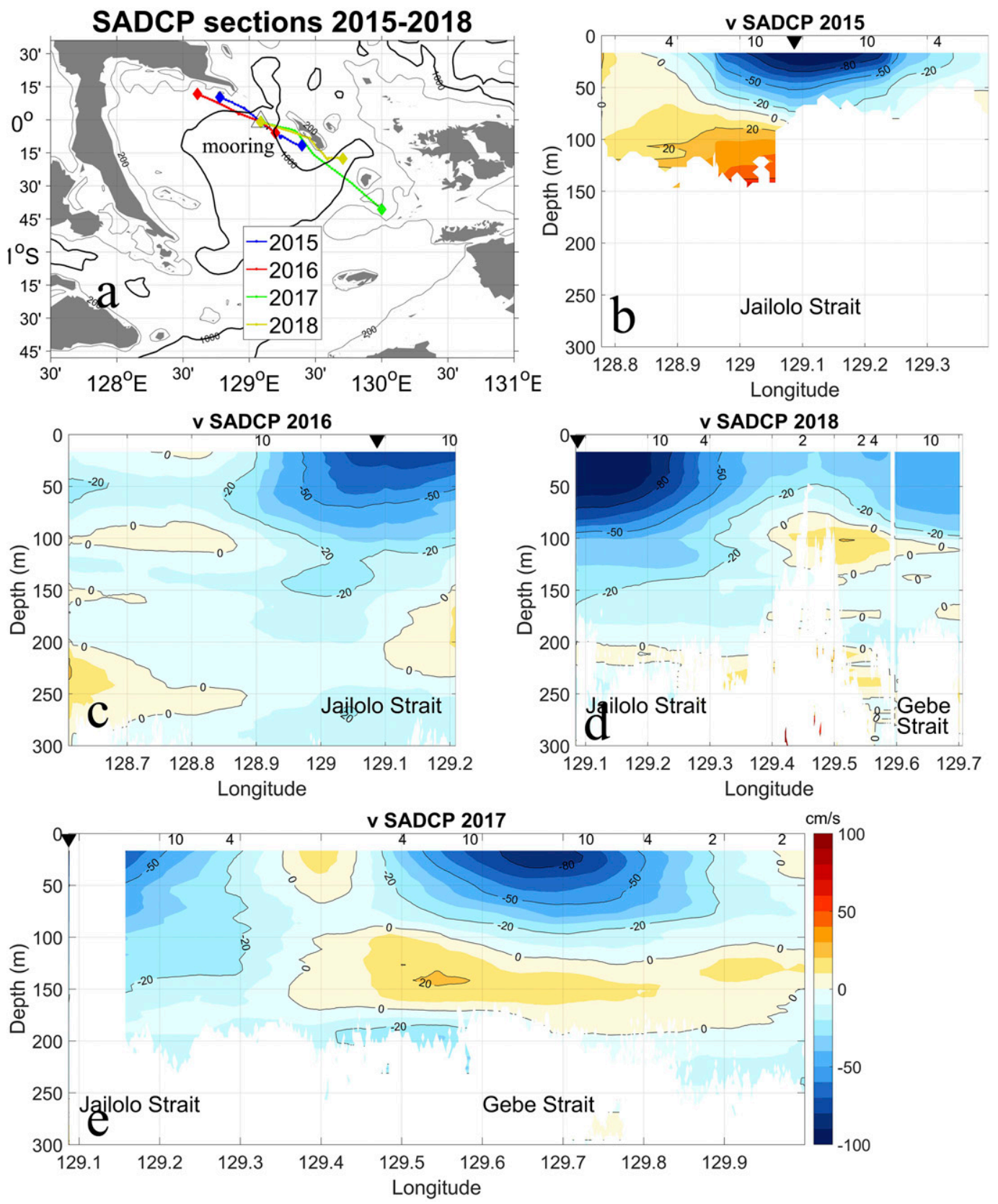

FIG. 3. (a) Shipboard ADCP sections across the Jailolo and the Gebe Straits during the 2015-18 mooring deployment and rotation cruises. The ends of the sections are marked with colored diamonds. The black-outlined triangle represents the mooring location. Also shown are the meridional velocities $\left(\mathrm{cm} \mathrm{s}^{-1}\right)$ in these sections as measured by the SADCP current meter in (b) 2015, (c) 2016, (e) 2017, and (d) 2018. The black triangles in the upper abscissas stand for the mooring locations. The numbers 2, 4, and 10 mark the locations of the 200-, 400-, and 1000-m isobaths in the sections.

are thus abandoned. Also, the blow down of the main float causes occasional data blank in the top. To fill the gap, linear extrapolation to the surface is conducted using the top two layers of $10-\mathrm{m}$ grid data. Examination of the SADCP data suggests that the meridional velocity become larger toward the surface, which justifies the linear extrapolation to the surface (Fig. 3). Although the SADCP data are transient snapshots in almost the same season with baroclinic tidal signals included, they are the only direct current observations that we have below the sea surface. Uncertainty of the extrapolation is estimated by comparing the transport estimates based on 
linear extrapolation, assuming constant velocity in the top layer above the shallowest grid, and linearly decreasing to zero at the surface. The maximum differences are used as the uncertainty estimate. At the bottom, which is much deeper at the mooring location than the sill depth of the Halmahera Sea, the nonslip condition is used to fill in the gap, with the estimate using the free-slip condition as a comparison to estimate the uncertainty.

The hourly data are filtered by a low-pass Butterworth filter with a cutoff period at 3 days to suppress the strong tidal signals. The time series are averaged into daily data for further analysis. The low-pass Butterworth filter with a cutoff period at 120 days is then applied to eliminate the intraseasonal variability. The surface winds from daily National Centers for Environmental PredictionNational Center for Atmospheric Research (NCEPNCAR) reanalysis 1 (https://www.esrl.noaa.gov/psd/data/ gridded/data.ncep.reanalysis.html) near the mooring location are used and also filtered by the 120-day low-pass Butterworth filter.

\section{b. The transport estimates}

The Jailolo Strait is about $60 \mathrm{~km}$ wide at the sea surface. According to the statistics of the velocity directions of the mooring measurements (figure omitted) and the shortest cross-strait distance at the surface, the alongstrait velocity (ASV) direction is defined as $20^{\circ}$ clockwise from due north. Negative ASV means flowing from the Pacific Ocean to the Indonesian seas. The ASV is assumed to be unchanged in the cross-strait direction between the $1000 \mathrm{~m}$ isobaths in a $32 \mathrm{~km}$ section in the middle of the strait and zero outside the section (Fig. 1, the section in red; Fig. 4, black dashed lines). The currents are not expected to vary strongly in the cross-strait direction of the Jailolo Strait due to the large deformation radius on the equator. This extrapolation is justified by the shipboard ADCP measurements in sections passing the mooring position during four cruises, showing strong meridional velocity between the $1000-\mathrm{m}$ isobaths consistently (Fig. 3). The mooring is evidently located near the maximum meridional velocity in the cross-strait sections, with the velocity decreasing quickly in the waters shallower than $1000 \mathrm{~m}$ toward the coasts. A transport based on linear interpolation to the coast using the nonslip condition is also calculated for uncertainty estimate.

In this study, the bathymetry data of ETOPO1 Global Relief Model obtained from National Oceanic and Atmospheric Administration (NOAA)/National Centers for Environmental Information (https://ngdc.noaa.gov/ $\mathrm{mgg} / \mathrm{global} / \mathrm{global.html}$ ) are used to derive the water depths of the sections of the shipboard ADCP measurements and of the sections for mooring transport estimation. The in situ measurements of the topography are made by a single-beam echo sounder during the cruises, although not precisely along the cross-strait section. These measurements are used to obtain the depths of the cross-strait section based on inverse distance weighting interpolation with an influence radius of $1.5 \mathrm{~km}$. The water depth of each grid point of the cross-strait section is estimated using several hundred echo-sounder measurements from 2015-18 cruises. The two bathymetry data are significantly different near the mooring location (Fig. 4), which brings uncertainty into the transport estimates.

\section{c. Ocean general circulation model simulations}

Simulations of three high-resolution ocean general circulation models are analyzed to study the structure of the currents near the Jailolo Strait. The Max Planck Institute for Meteorology Ocean Model (MPIOM) employs a tripolar grid with a horizontal resolution of $0.1^{\circ}$ at the equator (Storch et al. 2012). Eighty uneven vertical layers are used in the vertical. After being spun up, the model was driven by the NCEP-NCAR reanalysis winds starting from 1948. The mean velocity in the Jailolo Strait is averaged for the period from 2000 to 2011. The Ocean General Circulation Model for the Earth Simulator (OFES; Masumoto et al. 2004) employs a geographical horizontal grid with a resolution of $0.1^{\circ}$ longitude by $0.1^{\circ}$ latitude and a $z$-level vertical grid with 54 uneven levels. The hindcast simulation forced by the NCEPNCAR wind forcing during 2000-11 is used to form the mean velocity. The Global Ocean Forecasting System (GOFS) 3.1 operated by the Center for OceanAtmosphere Predictions Studies of Florida State University employs the Hybrid Coordinate Ocean Model (HYCOM) forced by the Navy Global Environmental Model (NAVGEM) atmospheric forcing and the U.S. Navy Coupled Ocean Data Assimilation system (Cummings 2005; Chassignet et al. 2009), with a horizontal resolution of $0.08^{\circ}$ and a 41-layer hybrid vertical grid. The 4-yr output of the experiment sequence from 56.3 to 93.0 starting from July 2014 is used to form the average velocity. The time coverage of the HYCOM simulation used here is shorter than that of the MPIOM and OFES simulations but overlaps the duration of the mooring observation in the Jailolo Strait. This new experiment fixed several known problems in the former experiment 53.X of the GOFS3.1 (https://www.hycom.org/ dataserver/gofs-3pt1/reanalysis). The mean ASVs in the cross-strait section are interpolated from the modeled mean velocities using bilinear interpolation.

The mean ASVs of the three high-resolution model simulations in the cross-strait section concentrate near the mooring site, with mean ASVs nearly zero on both flanks (Fig. 4), suggesting that the transport estimation 

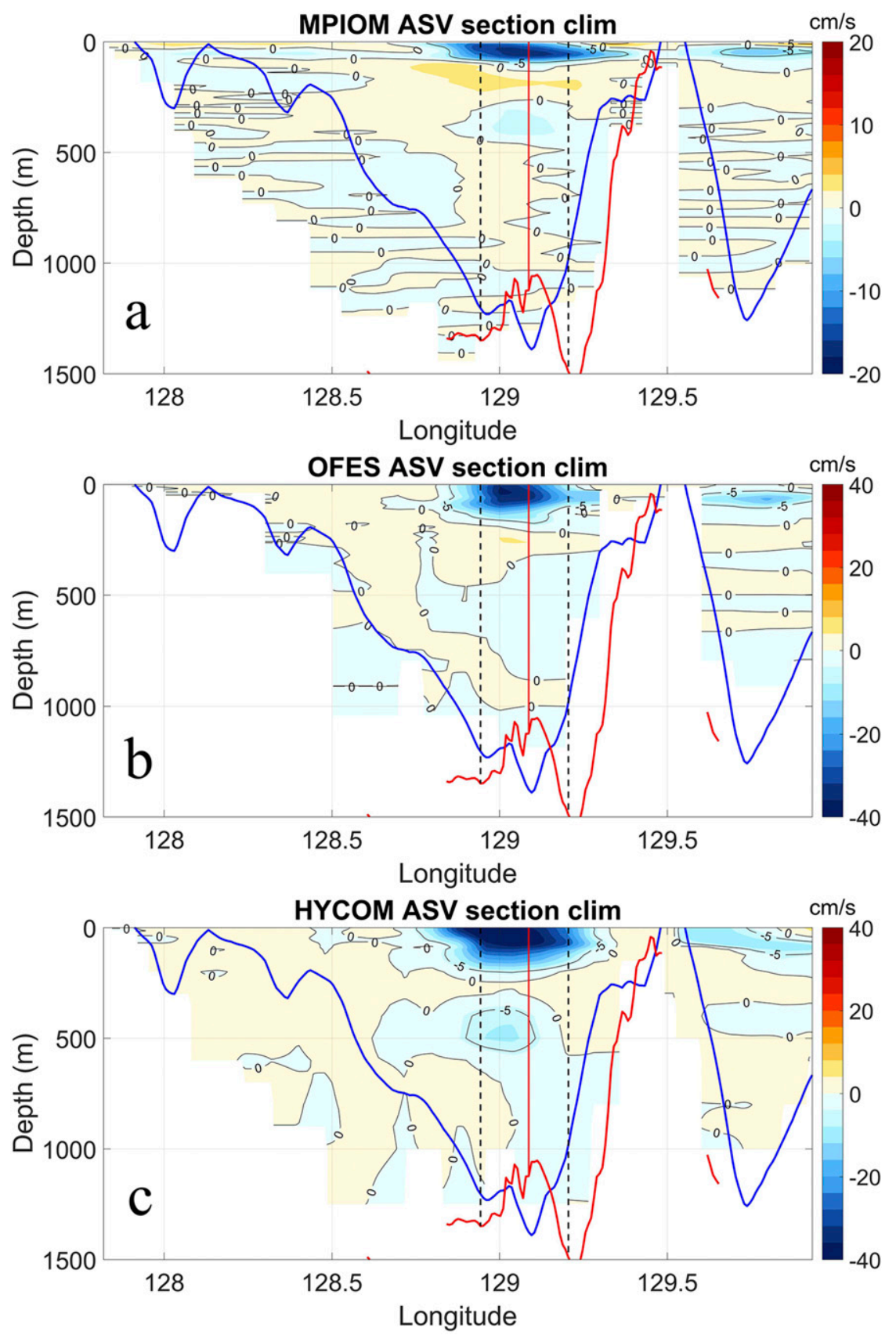

FIG. 4. Mean ASV $\left(\mathrm{cm} \mathrm{s}^{-1}\right.$ ) of the cross-strait sections in (a) MPIOM, (b) OFES, and (c) HYCOM high-resolution ocean models. The blue and red lines are the topography interpolated from ETOPO1 and shipboard echo-sounder measurements, respectively. The mooring location and the integration width of the strait in the transport calculation are shown as red solid and black dashed vertical lines. Note the different scales of the color shading in (a)-(c).

based on constant velocity in the deep waters near the mooring is a reasonable method. The mooring site is obviously located in the core of the ASV in all three highresolution model simulations, and the cross-strait integration roughly covers the strongest part of the ASVs. Details of the horizontal structure of the simulated ASVs are controlled by the model topography in the vicinity of the Halmahera Sea, which differs from the ETOPO1 data and the sounding measurements of the cruises (Fig. 4). The mean ASVs in the Jailolo Strait are different in different models and are generally not in good agreement with the mooring measurements. 


\section{d. Transport estimate based on satellite data}

The daily sea surface height (SSH) anomaly and mean sea level data are obtained from the AVISO multisatellite merged gridded product distributed by the Copernicus Marine and Environment Monitoring Service (CMEMS) (http://www.marine.copernicus.eu/). The $1 / 4^{\circ}$ gridded data are averaged in two boxes. One box is $1^{\circ}-2^{\circ} \mathrm{N}, 129^{\circ}-131^{\circ} \mathrm{E}$ in the Halmahera eddy north of the northern sill of the Halmahera Sea in the Pacific entrance. The other is $0.375^{\circ}-0.875^{\circ} \mathrm{S}, 128.875^{\circ}-129.375^{\circ} \mathrm{E}$ in the deepest part of the Halmahera Sea, excluding areas with depths shallower than $200 \mathrm{~m}$ (Fig. 1, blue-outlined boxes). The differences of SSH in the two boxes represent the upstream-downstream pressure gradient through the strait. The daily data are averaged into monthly means for further analysis. The gridded monthly ocean bottom pressure (OBP) anomaly data from the GRACE mission (https:/grace.jpl.nasa.gov/) are combined with the World Ocean Atlas 2013, version 2(WOA13v2), climatological hydrography (https://www.nodc.noaa.gov/OC5/woa13) to produce the absolute OBP data, which are also averaged in the two boxes. The averaged SSH anomalies and mean sea level have been tested to be not sensitive to the area and location of the boxes.

The monthly climatology of the satellite SSH is calculated based on the time series since 2003 . The monthly interannual anomalies are computed with the climatology subtracted from the total monthly SSH data and low-pass filtered using the Butterworth filter with a cutoff period at 13 months.

\section{Results}

In this section, the vertical structure and variability of the ASV of the mooring measurements are described, based on which the transport of the Jailolo Strait is estimated. The transport variability is also estimated based on the pressure gradient of the satellite data and compared with the mooring observations, based on which the seasonal and interannual variability of the transport in the Halmahera Sea is studied.

\section{a. Along-strait velocity}

The low-passed 2-yr series of ASV variability show a two-layer structure in the vertical (Fig. 5b). In the upper $200 \mathrm{~m}$, a strong annual cycle dominates the ASV, with strong inflows (maximum $>50 \mathrm{~cm} \mathrm{~s}^{-1}$ ) to the Halmahera Sea in boreal summer and weaker and shorter outflows (maximum $\sim 35 \mathrm{~cm} \mathrm{~s}^{-1}$ ) to the Pacific Ocean in boreal winter from December to April. The asymmetry of inflows and outflows results in a net mean throughflow of more than $20 \mathrm{~cm} \mathrm{~s}^{-1}$ in the upper $200 \mathrm{~m}$ (Fig. 5c). The currents in the upper ocean evidently flow against the local monsoonal winds (Fig. 5a), suggesting that the strong annual cycle of ASV in the upper Jailolo Strait is not controlled by the local wind forcing. Below $200 \mathrm{~m}$, the ASV is also dominated by an annual cycle, which is weaker and out of phase with that in the upper layer (Fig. 5b). The 2-yr mean ASV in the lower layer also flows toward the Indonesian seas (Fig. 5c), although it is weaker (less than $10 \mathrm{~cm} \mathrm{~s}^{-1}$ ) than that in the upper layer. The mean ASV profile is toward the Indonesian seas in the whole water column, except near the bottom where a weak northward flow was measured by the Aanderaa current meter at $1000 \mathrm{~m}$ in 2017.

The bottom Aanderaa current meter during the second deployment is $\sim 30 \mathrm{~m}$ deeper than the last bin of the downward-looking ADCP during the first deployment. It is possible that the bottom northward flow is confined below the $1000-\mathrm{m}$ depth. Because of this possibility, it is difficult to judge whether the observed northward flow at the bottom in 2017 is an interannual feature or the mean vertical structure of the currents. More observations are needed to study this phenomenon. The disagreement of the bottom ASV between the two deployments is unlikely to be due to different mooring locations, as they are only $25 \mathrm{~m}$ from each other.

This two-layer structure is confirmed from empirical orthogonal function (EOF) and power spectrum analyses (Fig. 6). The first EOF of the daily ASV is dominant, contributing to $60.4 \%$ of the variance with two opposite cores in the upper layer and near the 400-m depth (Fig. 6a) and with the principal components dominated by the annual cycle (figure omitted). The zero crossing of the first EOF is near $200 \mathrm{~m}$ (Fig. 6a), which is naturally used as the separation of the two layers for transport estimate.

The power spectrum density of the hourly ASV shows that the annual period is the most significant in the upper $200 \mathrm{~m}$ and at $400-500-\mathrm{m}$ depths, with low ASV variability at depths of 200-300 m between (Fig. 6b). This low variability is consistent with a stable inflow during the 2-yr measurements (Fig. 5b) with low standard deviation (Fig. 5c) at the 200-300-m depth. The semiannual variability is also concentrated at these core depths but is weaker than the annual cycle. The amplitudes of the intraseasonal variability of the ASV are found to be much weaker than those of the seasonal variability at the mooring location (Fig. 6b).

The harmonics have shown that the annual cycle of the ASVs above and below $200 \mathrm{~m}$ are out of phase to each other (Fig. 7a), with the maximum amplitude of about $50 \mathrm{~cm} \mathrm{~s}^{-1}$ at $80 \mathrm{~m}$ and of slightly over $10 \mathrm{~cm} \mathrm{~s}^{-1}$ between 400 and $500 \mathrm{~m}$. The amplitudes of the semiannual harmonic are weaker, with the maximum of 10 and $5 \mathrm{~cm} \mathrm{~s}^{-1}$ in the upper and lower layers, respectively, at 
NCEP wind $0^{\circ} 128.75^{\circ} \mathrm{E}$
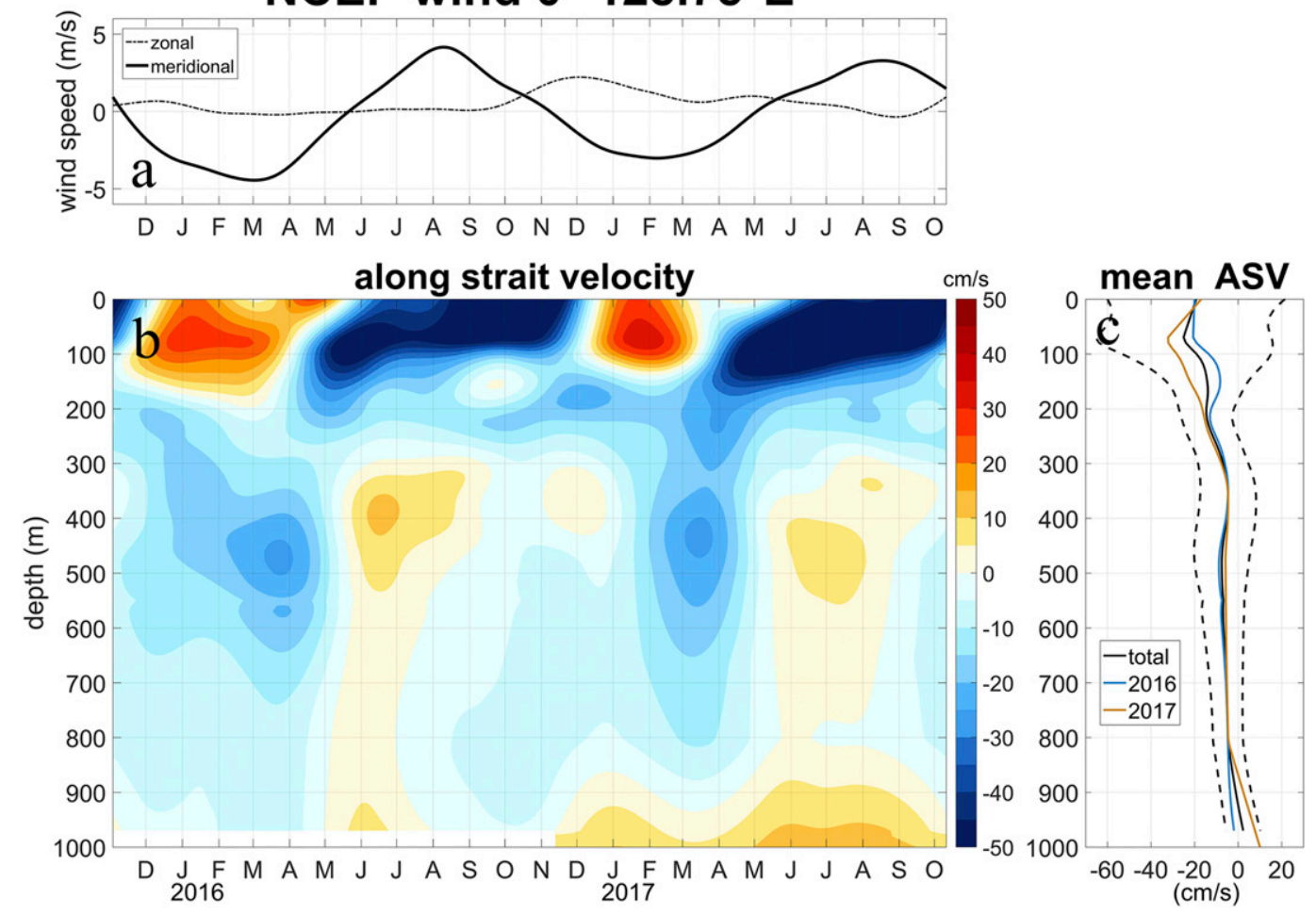

FIG. 5. (a) 120-day low-passed daily NCEP zonal and meridional winds $\left(\mathrm{m} \mathrm{s}^{-1}\right)$ near the Jailolo Strait. (b) 120-day low-passed ASV ( $\mathrm{cm} \mathrm{s}^{-1}$ ) of the 2-yr mooring measurements in the Jailolo Strait of the Halmahera Sea. (c) Mean ASV profiles ( $\mathrm{cm} \mathrm{s}^{-1}$ ) during the first year (2016; blue), the second year (2017; red), and the whole period (2016-17; black) of the mooring deployment. One standard deviation of the 2-yr daily ASV is shown as dashed black curves.

almost the same depth of the annual harmonics of each layer (Fig. 7b).

The two-layer structure of the variability may be explained by the baroclinic response to forcing. The second and the third baroclinic modes of the tropical oceans usually have zero crossings above $200 \mathrm{~m}$. The superposition of the first few modes leads to a reversed phase of the variability in the lower layer compared to that in the upper layer (figure omitted).

Previous analyses of water mass properties suggest that the South Pacific water carried by the New Guinea Coastal Current/Undercurrent (NGCC/NGCUC) contributes to the throughflow via the Halmahera Sea (Gordon 2005). The northward-flowing NGCC and NGCUC present a two-layer system with the surface NGCC in the upper $100 \mathrm{~m}$ reversing directions in boreal winter and the stable NGCUC northwestward flowing down below (Kuroda 2000; Ueki et al. 2003). Although the upper core of the ASV in the Jailolo Strait is at a similar depth as the NGCC, the lower core of variability at $400-500 \mathrm{~m}$ in the Jailolo Strait is deeper than the core of the NGCUC at $220 \mathrm{~m}$. In addition, unlike the out-of-phase relation of the two layers of the ASV in the Jailolo Strait, the seasonal variability of the NGCC and NGCUC is in phase. Both the NGCC and NGCUC become stronger during boreal summer and weaker in boreal winter, or the NGCC even reverses its direction due to the monsoon forcing (Ueki et al. 2003), whereas the upper currents in the Jailolo Strait flow against the monsoonal winds. These differences suggest that the current cores in the Jailolo Strait are not in simple connections with the NGCC/NGCUC. Synchronous observations are needed to investigate the dynamical relationship between the NGCC/NGCUC and the currents in the Halmahera Sea.

\section{b. Transport estimates based on mooring measurements}

Because only one mooring is used to estimate the transport, assuming unchanged ASV in the cross-strait direction in the waters deeper than $1000 \mathrm{~m}$ and zero velocity in the shallower waters, the variability of the transport is the same as that of the ASV in both the upper and lower layers, with the transport to the north 

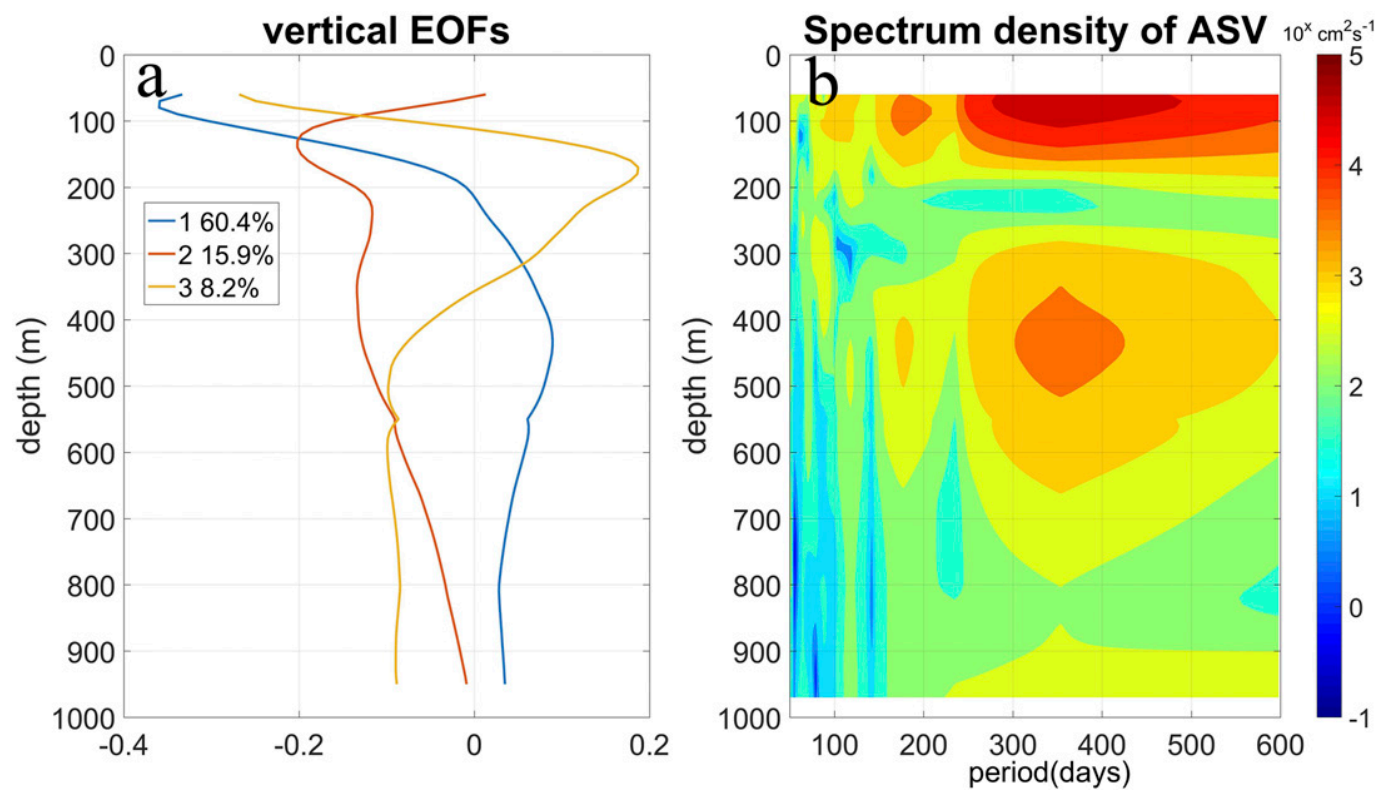

FIG. 6. (a) EOFs and (b) power spectrum density of the mooring ASV. The percentage numbers indicate the explained variances.

in boreal winter and to the south in boreal summer in the layer above $200 \mathrm{~m}$. In the lower layer, the transport is nearly the opposite (Fig. 8). The seasonal variability of the transport in the lower layer is consistent with the result based on the 1-yr moored current-meter data at 400and 700-m depths in 1993/94 (Cresswell and Luick 2001).

The mean transports of the upper and lower layers are nearly identical to each other at $-1.22 \mathrm{~Sv}$ to the south so that the mean full-depth transport during the 2-yr mooring period is $-2.44 \mathrm{~Sv}$, assuming linear extrapolation to the surface and the nonslip condition at the bottom. The mean transports of the first and second 1-yr periods of the measurements are -2.57 and $-2.27 \mathrm{~Sv}$, respectively, suggesting small year-to-year variability. The standard error of the mean transport is $0.42 \mathrm{~Sv}$ at the 95\% significance level, which is far below the mean transport, suggesting the robustness of the mean transport estimate from the Pacific Ocean to the Halmahera Sea. More statistics of the mean transport are listed in Table 1.

The full-depth mean transports are estimated to be $-2.48,-2.24$, and $-2.32 \mathrm{~Sv}$, if assuming constant surface currents, zero surface velocity, and the free-slip condition at the bottom, respectively (see section $2 b$ for the explanation of the extrapolation methods). Using the echo-sounder measurements to replace the ETOPO1 bathymetry results in the mean transport estimated to be $2.43 \mathrm{~Sv}$. The small difference in the transport estimates is due to the assumption of strong currents only in the central part of the strait, where the two topographies nearly compensate each other, and the linear interpolation of the currents deeper than $1000 \mathrm{~m}$ using the nonslip condition at the bottom. The maximum difference of the above estimates due to the use of the different boundary conditions in the vertical is only $0.20 \mathrm{~Sv}$, which is well below the standard error of the mean transport at $0.42 \mathrm{~Sv}$. Therefore, the mean transport and the uncertainties are estimated as $-2.44 \pm 0.42 \mathrm{~Sv}$.

We have also estimated the transports based on two shortest sections between the mooring site and the coasts. If the free-slip condition is applied at the coasts, the full-depth transport is as large as $-4.65 \mathrm{~Sv}$, assuming linear extrapolation to the surface and the nonslip condition at the bottom. If the nonslip condition is applied at the coasts, the full-depth mean transport is reduced to $-2.28 \mathrm{~Sv}$, close to the estimate of $-2.44 \mathrm{~Sv}$ based on the uniform sectional ASV profile above. The crossstrait structure of the ASV is difficult to estimate. The $-4.65 \mathrm{~Sv}$ estimate using the free-slip condition at the coasts is likely an overestimate of the Jailolo Strait transport. It is worth mentioning that the lower bound of the vertical integration of the transport estimate in this study is the ocean bottom, instead of the sill depth of the Halmahera Sea. The nonzero mean flows below the sill depth have been observed by the moored instruments, which suggest strong upwelling/downwelling currents in the Halmahera Sea. In contrast, the high-resolution ocean simulations suggest that the mean ASVs are nearly zero below the sill depths of the Halmahera Sea. The discrepancy may suggest lack of vertical mixing 

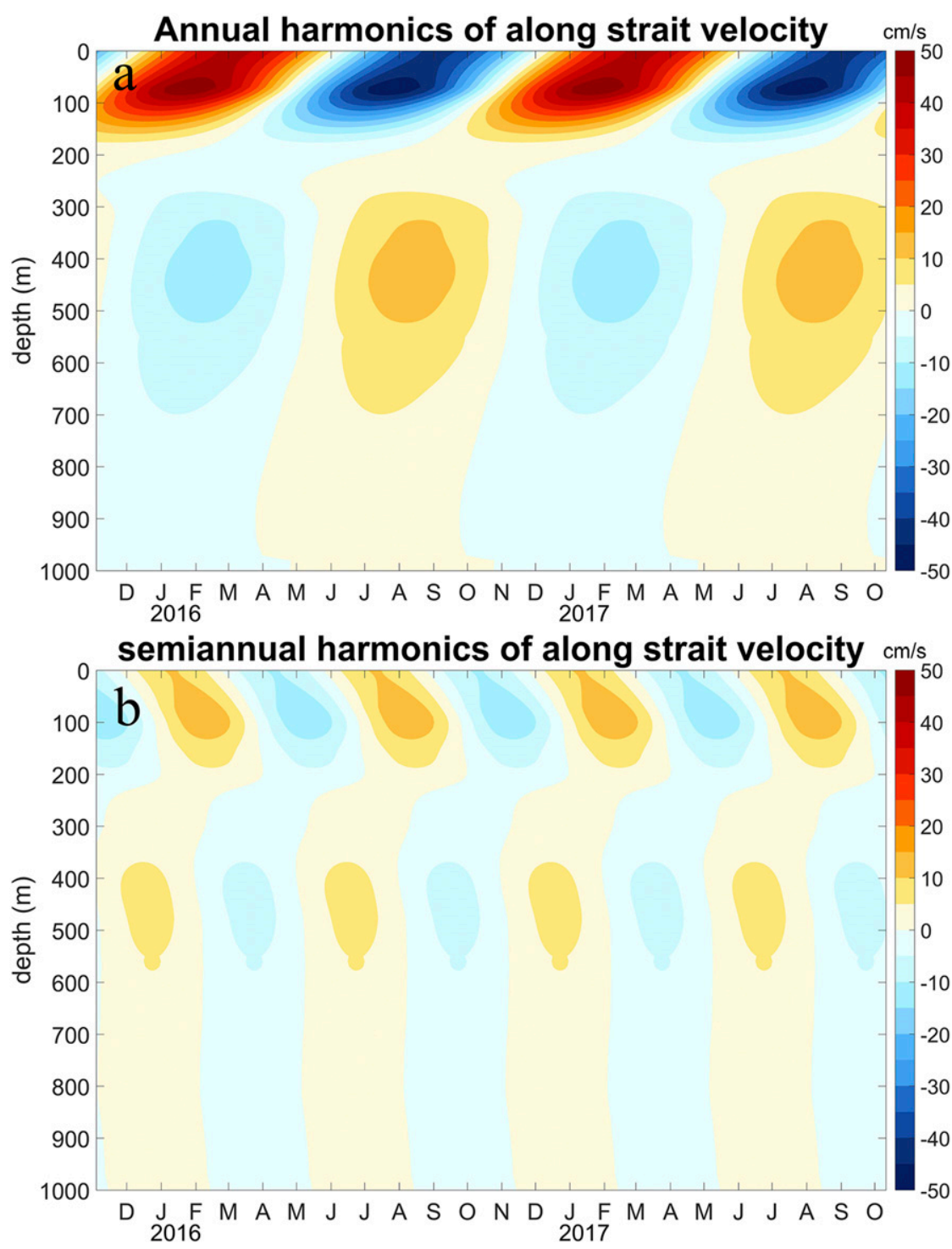

FIG. 7. (a) Annual and (b) semiannual harmonics of the mooring $\operatorname{ASV}\left(\mathrm{cm} \mathrm{s}^{-1}\right)$.

inside the Halmahera Sea and the absence of hydraulic overflow near the sill in the models (e.g., van Aken et al. 1991).

In contrast to the upper- and lower-layer transports, which are dominated by the annual cycles, the full-depth transport is dominated by a semiannual cycle, with minimum transports in boreal summer and winter whereas maximum transports in spring and fall (Fig. 8). The semiannual variability is evidently due to the cancellation of the annual cycle transports in the upper and lower layers. The mooring was deployed during the peak of the 2015/16 super El Niño. The ASV and transports do not show significant anomalies induced by the major anomalous event, which is surprising. The year-to-year differences of the transports in the upper and lower layers are generally lower than $1 \mathrm{~Sv}$, much smaller than the seasonal variability, suggesting that the interannual signals during the 2015/16 super El Niño and the 2016 La Niña events are small in the Halmahera Sea.

\section{c. Currents and transports in high-resolution model simulations}

All three models have reproduced the inflow core between 50 and $100 \mathrm{~m}$ successfully, with the maxima of 15, 30, and $40 \mathrm{~cm} \mathrm{~s}^{-1}$ in MPIOM, OFES, and HYCOM simulations, respectively (Fig. 4). The mean upper-layer velocities in MPIOM and OFES are comparable with the moored measurements, while those in HYCOM are much larger than the mooring observations (Figs. 4 and $5 c)$. Weak cores of outflow at 170,240 , and $250 \mathrm{~m}$, of the 


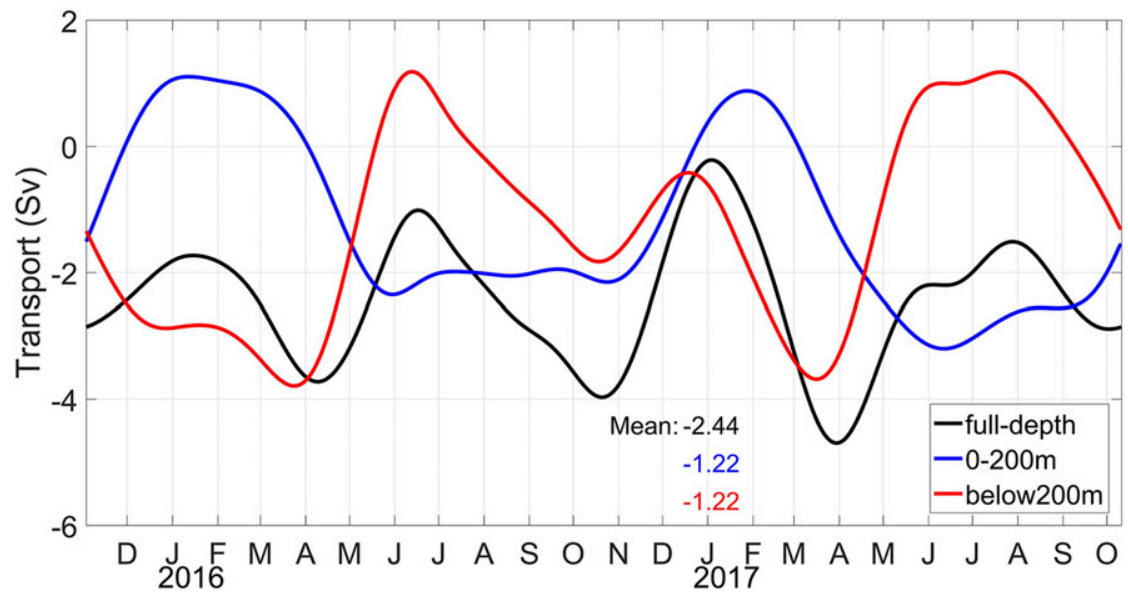

FIG. 8. Volume transports (Sv) of the Jailolo Strait. Blue, red, and black lines show transports for 0-200 m, below $200 \mathrm{~m}$, and for full depth. Numbers are the mean transports. The time series have been low passed by a Butterworth filter with a cutoff period at 120 days. More statistics of the transports are listed in Table 1.

three models, respectively, with the maximum larger than $2 \mathrm{~cm} \mathrm{~s}^{-1}$, especially in MPIOM and OFES simulations, are not in agreement with the moored ADCP measurements. Further below, cores of inflow at 400500-m depths in the MPIOM and HYCOM simulations are a little weaker than in the observations. The simulated ASVs nearly vanish below the sill depths of the Halmahera Sea, which are different from the observations. The mean velocity below the sill depth is discussed above in section $3 \mathrm{~b}$.

The simulated mean transports through the Jailolo Strait are $-0.45,-1.29$ and $-2.51 \mathrm{~Sv}$ in the MPIOM, OFES, and HYCOM simulations. All models have underestimated the transport in the lower layer below about $100 \mathrm{~m}$, especially below the sill depths of each model. As a result, the total transports of the Jailolo Strait are underestimated in the MPIOM and OFES simulations. In HYCOM, overestimated transports in the upper layer and underestimated transports in the lower layer result in a simulated total transport similar to the observed estimate of $-2.44 \mathrm{~Sv}$.

The errors of transport estimation using single mooring measurements are examined using the high-resolution model simulations. The simulated transports are estimated to be -0.47 or $-0.51 \mathrm{~Sv},-1.28$ or $-1.12 \mathrm{~Sv}$, and -2.25 or $-2.45 \mathrm{~Sv}$, assuming constant velocity near the mooring site in the former or the nonslip condition at the nearest coasts in the latter values, in the MPIOM, OFES, and HYCOM simulations, respectively (Table 2). The relative errors of the transport estimates based on ASV profiles at the mooring site are no more than $15 \%$, suggesting the validity of the transport estimate based on the single mooring measurements in this study.

\section{d. Transport estimates based on satellite data}

The seasonal and interannual variabilities of the Halmahera Sea transport have also been estimated using satellite $\mathrm{SSH}$ and OBP anomalies. The long time series of SSH and OBP data since 2003 provide a vantage insight of the seasonal and interannual variabilities compared to the 2 -yr mooring data. The SSH data in the boxes upstream and downstream of the Halmahera Sea transport show significant seasonal to interannual variabilities (Fig. 9a). The sharp decrease of sea level during 2015-16 is easily identified in both boxes (Fig. 9a), with the SSH differences showing nearly uninterrupted regular annual cycles during the super El Niño (Fig. 9b), however.

Assuming the transport through a narrow strait is forced by the upstream-downstream pressure gradient, the transport through the Jailolo Strait can be estimated using the satellite SSH and OBP data according to the following formula developed by Song (2006), combining the geostrophic control formula (Garrett and Toulany 1982) with hydraulic control theory (Whitehead et al. 1974):

TABLE 1. The statistics of the estimated transport (Sv) through the Jailolo Strait. Standard errors are calculated at a 95\% significance level.

\begin{tabular}{lccc}
\hline \hline & Mean & Std dev & Std error \\
\hline Full depth & -2.44 & 1.68 & 0.42 \\
0-200 m & -1.22 & 1.51 & 1.02 \\
Below 200 m & -1.22 & 1.97 & 0.60 \\
Full depth 2016 & -2.57 & 1.52 & 0.49 \\
Full depth 2017 & -2.27 & 1.85 & 0.73 \\
\hline
\end{tabular}


TABLE 2. The transports (Sv) through the Jailolo Strait in high-resolution model simulations based on different calculation methods.

\begin{tabular}{lccc}
\hline \hline & MPIOM & OFES & HYCOM \\
\hline True transport & -0.45 & -1.29 & -2.51 \\
Constant ASV near mooring site & -0.47 & -1.28 & -2.25 \\
Nonslip condition at the coasts & -0.51 & -1.12 & -2.45 \\
\hline
\end{tabular}

$$
Q=\frac{r_{1} g}{\lambda+r_{1} f} H_{1} \Delta \eta+\frac{r_{2} g}{\lambda+r_{2} f} H_{2}\left(\Delta p_{b}-\Delta \eta\right)
$$

where subscripts 1 and 2 stand for the upper and lower layers, $\lambda$ is the bottom friction coefficient, $r$ is the ratio of the width to the length of the strait, $H$ is the layer thickness, $g$ is the gravity constant, $f$ is the Coriolis parameter, and $\Delta \eta$ and $\Delta p_{b}$ are the differences of the SSH and OBP between the upstream and downstream basins of the strait. In this formula, the transports of the upper and lower layers are proportional to the pressure gradients $\Delta \eta$ and $\Delta p_{b}-\Delta \eta$, the signs of which determine the direction of the transports. This formula has been applied to estimate the transports in the Sibutu Passage (Qu and Song 2009) and the Makassar Strait (Susanto and Song 2015) successfully. Note that the mean transport estimated from Eq. (1) suffers from an inaccurate satellite mean sea level and OBP and is sensitive to the specification of the parameters in the formula.

The upper-layer transport estimated from the satellite data based on Eq. (1) shows the maximum in boreal summer and the minimum or even reverses in some years in boreal winter (Fig. 9c), consistent with the transport variability of the mooring observations (Fig. 8). The annual variability of the OBP gradient is much smaller than the SSH gradient (Fig. 9b) so that the lower-layer transport variability is also dominated by the SSH forcing, except for a phase opposite to the upper-layer transport variability (Fig. 9c). The cancellation of the annual cycles in the upper- and lower-layer transports results in a much weaker annual cycle of the total transport. The seasonal variability of the transport is evidently reproduced successfully by Eq. (1) using the SSH and OBP data, except for the mean and the amplitudes of the transport variability (Fig. 9c). The amplitudes of the seasonal cycle and the mean transport are sensitive to the parameters in Eq. (1), which will be discussed in the next section.

The area-averaged monthly climatological SSH in the upstream box in the Halmahera eddy shows dominant semiannual variability with a weak annual cycle (Fig. 10a). The semiannual variability in the far western equatorial Pacific is forced primarily by the internal nonlinear dynamics through frequency doubling, combined with a weak semiannual forcing of the local monsoon (Yuan 2005). The SSH in the southern Halmahera Sea in the downstream box has much stronger and dominant annual variability than in the Halmahera eddy, the dynamics of which are not clear at present. The strong annual cycle in the Indonesian seas is likely forced by the Ekman pumping of the monsoon (Gordon 2005). Further studies are needed to attest the dynamics of the wind forcing. The disparate seasonal cycles of the western equatorial Pacific and Halmahera Sea SSH suggest that they are driven by different dynamical processes. The different seasonal cycles are not local phenomena in small regions (Fig. 11). The seasonal SSH in the western equatorial Pacific Ocean is dominated by the semiannual variability. In the Indonesian seas, however, there is stronger annual variability of SSH with a uniform phase. The opposite phases of the annual harmonics between the Pacific Ocean and the Indonesian seas show a front at the entrance of the ITF. The significant different seasonal harmonics on the different sides of the Jailolo Strait indicate that the analyses are not sensitive to the box selection.

The low-passed interannual anomalies of the SSH in the two boxes are found to be highly correlated with each other (Fig. 10b). The differences between the western equatorial Pacific and the Halmahera Sea SSH do not show significant interannual variability during the 2015/16 super El Niño (Fig. 9b). The amplitude of the interannual SSH difference is much smaller than the seasonal cycle difference (Figs. 10a,b). The mooring measurements have shown that the interannual current anomalies in the Jailolo Strait are small during the 2015/16 super El Niño event, suggesting lack of significant El Niño signals propagating into the Indonesian seas through the Halmahera Sea. The highly correlated SSH between the western equatorial Pacific and the Halmahera Sea may be due to the propagation of the interannual signals through other channels of the Indonesian seas, like the Makassar Strait and the Maluku Channel (Gordon et al. 1999; Susanto et al. 2012; Sprintall et al. 2014; Yuan et al. 2018a), or through the atmospheric bridge. The fast propagation of the equatorial and coastal Kelvin waves in the Indonesian seas can explain the nearly synchronous interannual variability of SSH in the western Pacific and inside the Indonesian seas. The satellite pressure data since 2003 cover several interannual events. The pressure difference of the interannual anomalies is about one order smaller than that of the seasonal cycle during this period (Fig. 10).

Existing studies have suggested the propagation of ENSO signals from the western Pacific Ocean to the eastern Indian Ocean along the west coasts of the New Guinea and the Australia continent (Clarke and Liu 1994; Wijffels and Meyers 2004; McClean et al. 2005). Wijffels and Meyers (2004) proposed that the Halmahera Sea is where the Rossby waves from the western Pacific Ocean excite coastally trapped waves to propagate toward the 

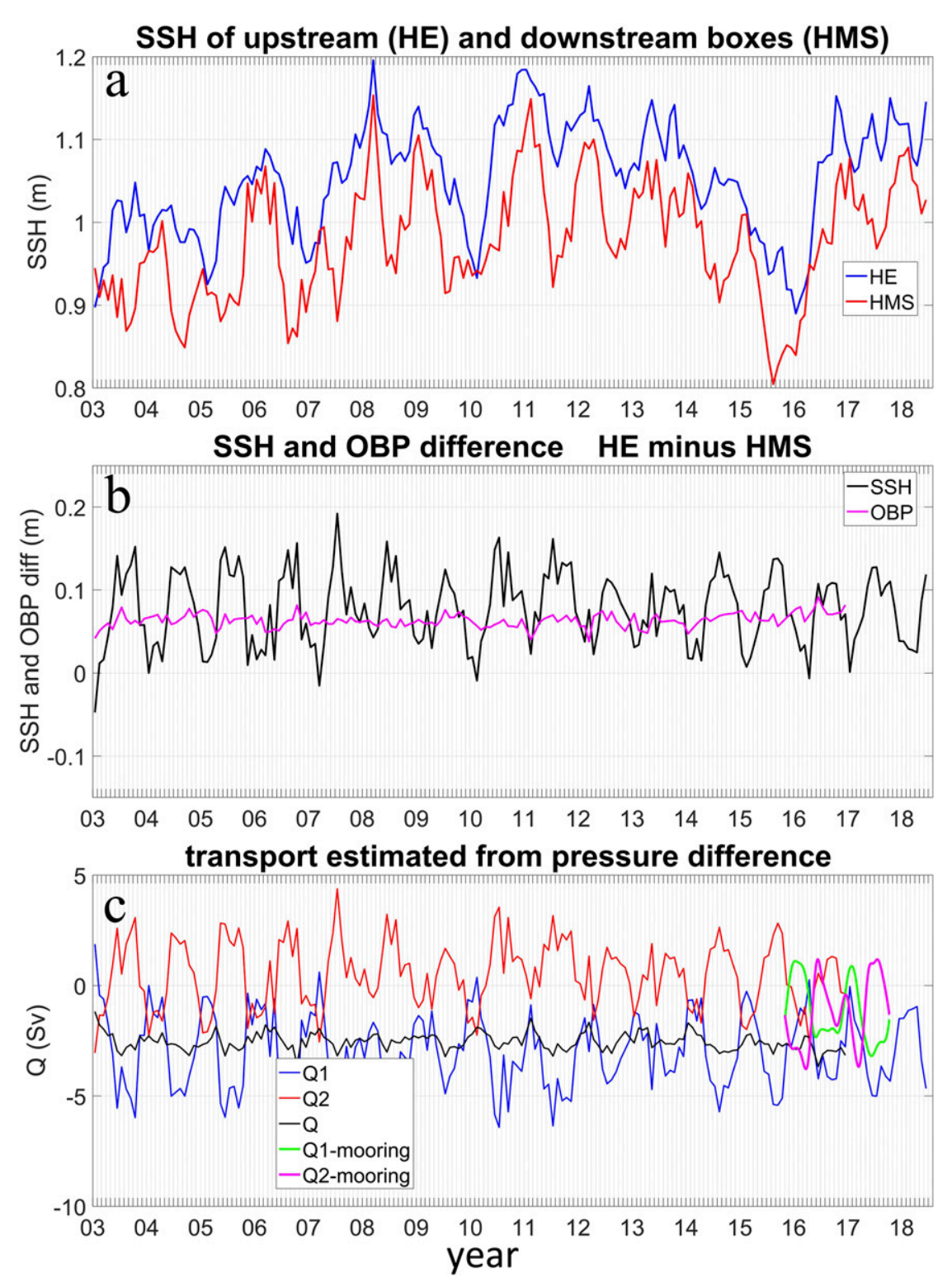

FIG. 9. (a) Monthly SSH (m) of the upstream (Halmahera eddy, labeled HE; blue) and downstream (southern Halmahera Sea, labeled HMS; red) boxes of the Jailolo Strait. (b) SSH (black) and OBP (purple) differences between the upstream and downstream boxes. (c) Transports estimated from the pressure differences based on Eq. (1); Q1 (blue), Q2 (red), and Q (black) show the upper layer, lower layer, and total transports. The low-passed time series of the mooring upper (green) and lower transports (purple) are shown for comparison.

eastern Indian Ocean. That hypothesis is not supported by the 2 -yr moored measurements or the long-term satellite observations.

\section{Discussion}

\section{a. Transport through the eastern Halmahera Sea}

In addition to the Jailolo Strait, there is another channel east of the Gebe Island (called the Gebe
Strait in the following text) deeper than $1000 \mathrm{~m}$ in the eastern Halmahera Sea, which has an $\sim 400$-m-deep sill in the north according to ETOPO1 topography (Fig. 1). This strait has never been covered by mooring measurements historically. Its transport is not known to date. The 2017 and 2018 cruises have shown that the meridional velocity in the Gebe Strait and the Jailolo Strait are comparable and in the same direction with each other in upper $100 \mathrm{~m}$ (Fig. 3). The one 

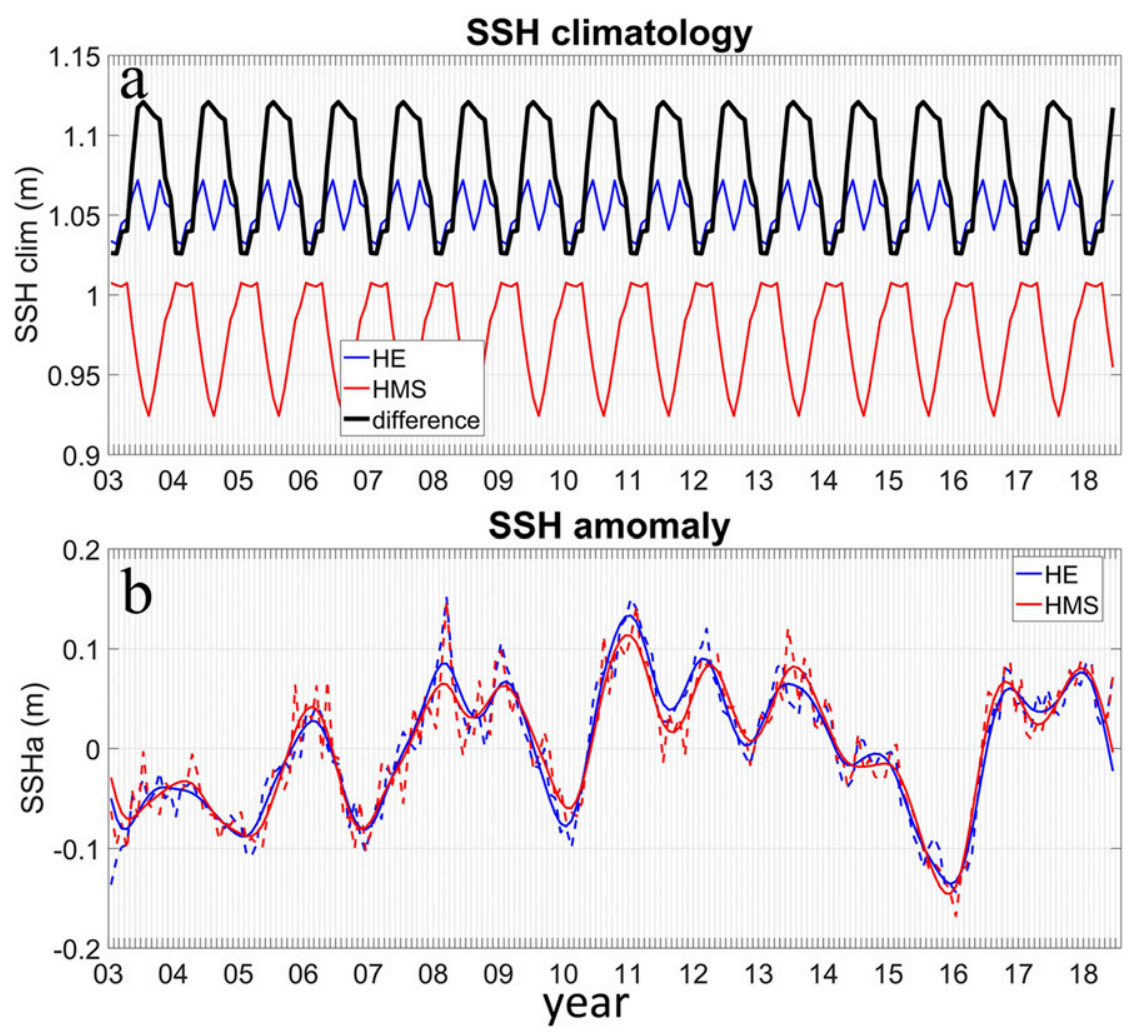

FIG. 10. (a) Monthly climatological SSH (m) of the upstream (blue) and downstream (red) boxes of the Jailolo Strait and their difference (black) based on the 2003-17 time series. (b) SSH anomalies (dashed lines) in the upstream (blue) and downstream (red) boxes. Solid lines in (b) represent the monthly anomalies low passed by a Butterworth filter with a cutoff period at 13 months.

time measurement based on the SADCP section in the 2017 cruise suggests a transport of $-1.8 \mathrm{~Sv}$ above $200 \mathrm{~m}$ in the Gebe Strait.

It is likely that the current variations in the two straits are controlled by similar dynamics and are consistent with each other. So including the transport of the Gebe Strait should not alter the phasing of the total transport from the western Pacific Ocean to the Halmahera Sea. The transport estimate based on satellite pressure difference has theoretically included the Gebe Strait transport, since the pressure force from the western Pacific Ocean to the southern Halmahera Sea through the Jailolo Strait and the Gebe Strait is the same. The consistent transport variability estimated from the mooring data and from the satellite pressure difference suggests that either the transport variabilities in the Jailolo Strait and the Gebe Strait are similar or the variability of the total transport through the two straits is dominated by the former. Since 2018, a new mooring has been running in the Gebe Strait. And we plan to deploy another mooring in the Jailolo
Strait to obtain a better estimate of the transport in the future.

\section{b. Mean transport estimation based on the pressure difference}

According to Eq. (1), the pressure differences determine the direction of the transports, but mean transports and amplitudes of the variability are scaled by several parameters. We use $r_{1}=0.1$ and $r_{2}=0.05$ as the ratios of the width to the length of the strait based on ETOPO1 Global Relief Model. The smaller ratio in the lower layer is due to the narrower strait with increasing depths. The same bottom friction coefficient of $5 \times 10^{-6} \mathrm{~s}^{-1}$ is used as in Qu and Song (2009) and Susanto and Song (2015). The separation of the upper and lower layers should be at the thermocline in the tropical ocean (Song 2006). Thus, we use $H_{1}=200 \mathrm{~m}$ based on the CTD profiles during the cruises (Fig. 2) and the characteristics of the two-layer system of the currents from the mooring measurements shown above. The $H_{2}=350 \mathrm{~m}$ is chosen as the thickness between the bottom of the upper layer and the outer sill depth of the Halmahera Sea. Because 

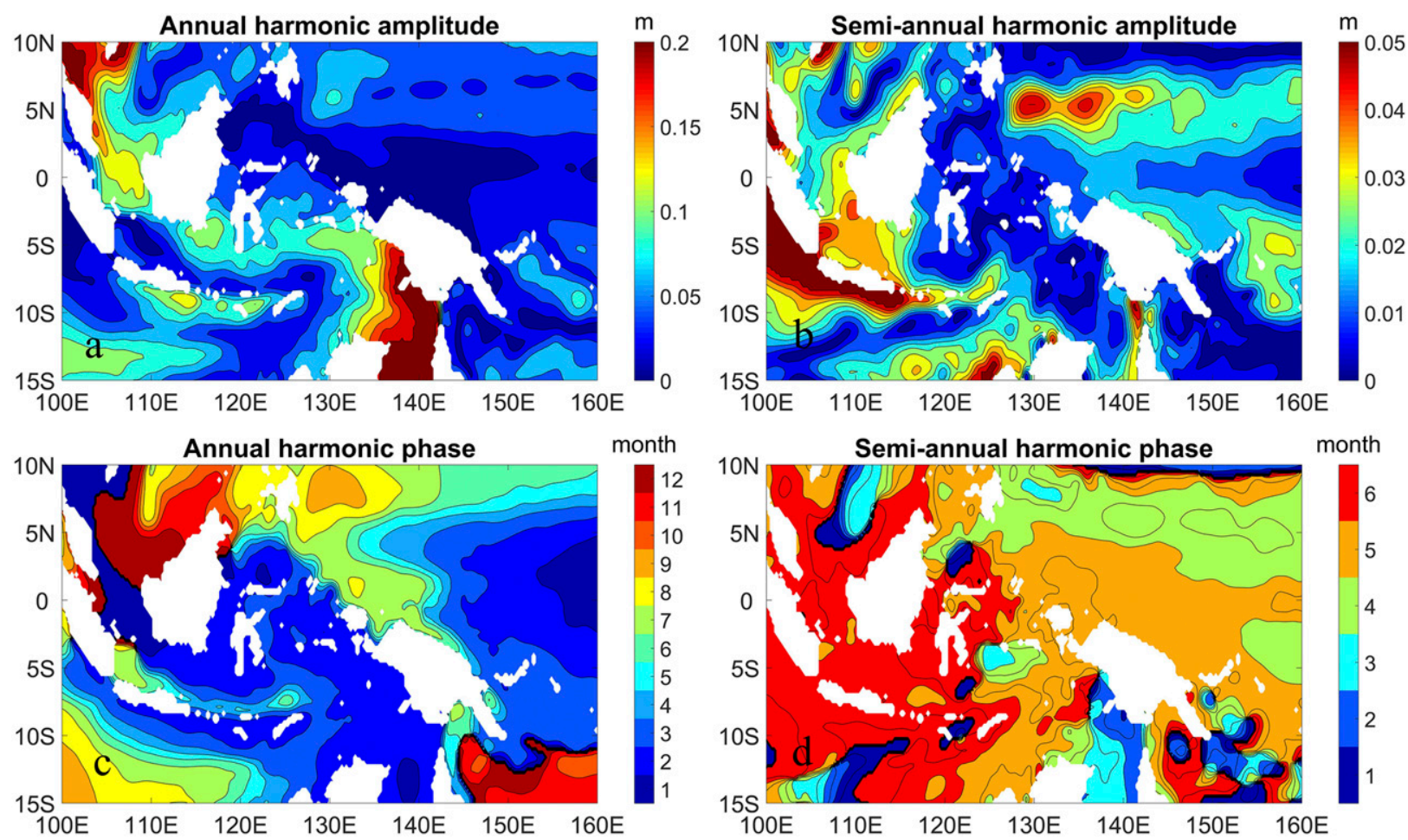

FIG. 11. Amplitudes (m) and phases (months) of (a),(c) annual and (b),(d) semiannual harmonics of the sea level anomaly (SLA) based on the AVISO satellite gridded SLA product. Note the different scales in annual and semiannual amplitudes.

the Coriolis parameter is very small near the equator, friction dominates the denominators in Eq. (1), that is, $\lambda \gg r f$. So the transports are roughly proportional to the ratio of the width to length $r$ and the thicknesses of the layer $H$, and inversely related to the bottom friction $\lambda$. The satellite pressure difference suggests a mean transport of $-2.55 \mathrm{~Sv}$ based on the above choice of the parameters, close to the mean transport estimated from the mooring data. However, the estimated transport is sensitive to the choice of the parameters and is subject to the errors of the satellite mean SSH and OBP, suggesting large uncertainty in the mean transport and the amplitudes of the variabilities estimated from the satellite data.

\section{Conclusions}

In this paper, the currents of the Halmahera Sea are studied based on current-meter data of a 2-yr mooring from November 2015 through October 2017 in the Jailolo Strait. The mean along-strait velocity is shown to flow toward the Indonesian seas throughout the water column except at the bottom, where a northward flow during 2017 is observed. The variability of the subtidal currents is found to be characterized by a two-layer system with dominant annual cycles. In the upper $200 \mathrm{~m}$, the currents are northward to the Pacific Ocean during December through April, but stronger and southward for the rest of the year with the maximum velocity larger than $50 \mathrm{~m} \mathrm{~s}^{-1}$. Below $200 \mathrm{~m}$, the currents are also dominated by an annual cycle but with an opposite phase. The amplitudes of annual harmonics of the ASV in the upper and lower layers are concentrated at the depths of 80 and $400-500 \mathrm{~m}$, with amplitudes of 50 and $10 \mathrm{~m} \mathrm{~s}^{-1}$, respectively.

The 2-yr mean transport of the Jailolo Strait is estimated to be $-2.44 \pm 0.42 \mathrm{~Sv}$ to the Indonesian seas based on the mooring data. The largest uncertainty may exist in the horizontal extrapolation, which, however, is supported by the SADCP measurements and high-resolution model simulations. The mean transport based on satellite data is estimated to be $-2.55 \mathrm{~Sv}$, with large uncertainties associated with parameter choices and data errors.

The pressure difference between the far equatorial western Pacific Ocean and the Indonesian Seas is proposed to drive the variability of the transports through the Jailolo Strait. Especially, the seasonal variability of the transports in both upper and lower layers is dominated by the annual cycle of SSH in the Indonesian Seas. The cancellation of out-of-phase upper- and lower-layer annual cycle transports results in a semiannual variation of the full-depth transport through the Jailolo Strait. 
The interannual transport in the Jailolo Strait during the 2015/16 super El Niño is found to be much smaller than the seasonal cycle based on the mooring observations, suggesting that most of El Niño signal did not propagate into the Indonesian seas through the Halmahera Sea. The observation challenges the existing studies suggesting a major interbasin waveguide from the western Pacific Ocean through the Halmahera Sea to the west coasts of the New Guinea and the Australia continent and to the eastern Indian Ocean.

Acknowledgments. This study is supported by NSFC (41421005, 41720104008, 91858204, and 41876025), CAS (XDA11010205), QMSNL (2018SDKJ0104-02), and the Shandong Provincial projects (U1606402). We thank the crews of R/V Baruna Jaya VIII and the technicians from $\mathrm{RCO} / \mathrm{LIPI}$ for the successful cruises. We also thank AVISO, JPL, and NOAA for sharing their datasets. The mooring data used in this study can be accessed online (http://itf.qdio.ac.cn/xzlxz/).

\section{REFERENCES}

Chassignet, E. P., and Coauthors, 2009: US GODAE global ocean prediction with the HYBRID Coordinate Ocean Model (HYCOM). Oceanography, 22, 64-75, https://doi.org/10.5670/ oceanog.2009.39.

Clarke, A., and X. Liu, 1994: Interannual sea level in the northern and eastern Indian Ocean. J. Phys. Oceanogr., 24, 1224-1235, https:// doi.org/10.1175/1520-0485(1994)024<1224:ISLITN>2.0.CO;2.

Cowley, R., B. Heaney, S. Wijffels, L. Pender, J. Sprintall, S. Kawamoto, and R. Molcard, 2008: INSTANT Sunda data report description and quality control. CSIRO, 288 pp., http:// www.marine.csiro.au/ cow074/INSTANTdataQC_v4.pdf.

Cresswell, G., and J. Luick, 2001: Current measurements in the Halmahera Sea. J. Geophys. Res., 106, 13 945-13 951, https:// doi.org/10.1029/2000JC000688.

Cummings, J. A., 2005: Operational multivariate ocean data assimilation. Quart. J. Roy. Meteor. Soc., 131, 3583-3604, https:// doi.org/10.1256/qj.05.105.

Egbert, G. D., and S. Y. Erofeeva, 2002: Efficient inverse modeling of barotropic ocean tides. J. Atmos. Oceanic Technol., 19, 183-204, https://doi.org/10.1175/1520-0426(2002)019<0183: EIMOBO $>2.0 . \mathrm{CO} ; 2$.

Fang, G., and Coauthors, 2010: Volume, heat, and freshwater transports from the South China Sea to Indonesian seas in the boreal winter of 2007-2008. J. Geophys. Res., 115, C12020, https://doi.org/10.1029/2010JC006225.

Fu, L.-L., 1986: Mass, heat and freshwater fluxes in the south Indian Ocean. J. Phys. Oceanogr., 16, 1683-1693, https://doi.org/ 10.1175/1520-0485(1986)016<1683:MHAFFI > 2.0.CO;2.

Garrett, C. J. R., and B. Toulany, 1982: Sea level variability due to meteorological forcing in the northeast of St. Lawrence. J. Geophys. Res., 87, 1968-1978, https://doi.org/10.1029/ JC087iC03p01968.

Godfrey, J. S., 1996: The effect of the Indonesian Throughflow on ocean circulation and heat exchange with the atmosphere: A review. J. Geophys. Res., 101, 12 217-12237, https://doi.org/ 10.1029/95JC03860.
Gordon, A. L., 2005: Oceanography of the Indonesian seas and their throughflow. Oceanography, 18, 14-27, https://doi.org/ 10.5670/oceanog.2005.01.

- and R. Fine, 1996: Pathways of water between the Pacific and Indian Oceans in the Indonesian seas. Nature, 379, 146-149, https://doi.org/10.1038/379146a0.

— Indonesian seas: Model and observations. J. Phys. Oceanogr., 29, 198-216, https://doi.org/10.1175/1520-0485(1999)029<0198: TSOTIS $>2.0$. CO 2 .

, R. D. Susanto, and A. Ffield, 1999: Throughflow within Makassar Strait. Geophys. Res. Lett., 26, 3325-3328, https:// doi.org/10.1029/1999GL002340.

_ C. F. Giulivi, and G. Ilahude, 2003: Deep topographic barriers within the Indonesian seas. Deep-Sea Res. II, 50, 22052228, https://doi.org/10.1016/S0967-0645(03)00053-5.

, R. D. Susanto, A. Ffield, B. A. Huber, W. Pranowo, and S. Wirasantosa, 2008: Makassar Strait throughflow, 2004 to 2006. Geophys. Res. Lett., 35, L24605, https://doi.org/10.1029/ 2008GL036372.

- - and Coauthors, 2010: The Indonesian Throughflow during 2004-2006 as observed by the INSTANT program. Dyn. Atmos. Oceans, 50, 115-128, https://doi.org/10.1016/ j.dynatmoce.2009.12.002.

_ and interannual variability: An overview. J. Geophys. Res. Oceans, 124, 3724-3736, https://doi.org/10.1029/2018JC014502.

$\mathrm{Hu}, \mathrm{X}$., and Coauthors, 2019: Interannual variability of the Sulawesi Sea circulation forced by Indo-Pacific planetary waves. J. Geophys. Res. Oceans, 124, 1616-1633, https:// doi.org/10.1029/2018JC014356.

Koch-Larrouy, A., A. Atimadipoera, P. van Beek, G. Madec, J. Aucan, F. Lyard, J. Grelet, and M. Souhaut, 2015: Estimates of tidal mixing in the Indonesian archipelago from multidisciplinary INDOMIX in-situ data. Deep-Sea Res. I, 106, 136153, https://doi.org/10.1016/j.dsr.2015.09.007.

Kuroda, Y., 2000: Variability of currents off the northern coast of New Guinea. J. Oceanogr., 56, 103-116, https://doi.org/10.1023/ A:1011122810354.

Liu, H., W. Li, and X. Zhang, 2005: Climatology and variability of the Indonesian Throughflow in an eddy-permitting oceanic GCM. Adv. Atmos. Sci., 22, 496-508, https://doi.org/10.1007/ BF02918483.

Masumoto, Y., and T. Yamagata, 1996: Seasonal variations of the Indonesian throughflow in a general ocean circulation model. J. Geophys. Res., 101, 12 287-12 293, https://doi.org/10.1029/ 95JC03870.

- and Coauthors, 2004: A fifty-year eddy-resolving simulation of the world ocean-Preliminary outcomes of OFES (OGCM for the Earth Simulator). J. Earth Simul., 1, 35-56.

McClean, J. L., D. P. Ivanova, and J. Sprintall, 2005: Remote origins of interannual variability in the Indonesian Throughflow region from data and a global Parallel Ocean Program simulation. J. Geophys. Res., 110, C10013, https://doi.org/10.1029/ 2004JC002477.

Metzger, E. J., H. E. Hurlburt, X. Xu, J. F. Shriver, A. L. Gordon, J. Sprintall, R. D. Susanto, and H. M. van Aken, 2010: Simulated and observed circulation in the Indonesian seas: $1 / 12^{\circ}$ global HYCOM and the INSTANT observations. Dyn. Atmos. Oceans, 50, 275-300, https://doi.org/10.1016/j.dynatmoce.2010.04.002.

Meyers, G., 1996: Variation of Indonesian Throughflow and the El Niño-Southern Oscillation. J. Geophys. Res., 101, 12 25512 263, https://doi.org/10.1029/95JC03729. 
Qu, T., and Y. T. Song, 2009: Mindoro Strait and Sibutu Passage transports estimated from satellite data. Geophys. Res. Lett., 36, L09601, https://doi.org/10.1029/2009GL037314.

Song, Y. T., 2006: Estimation of interbasin transport using ocean bottom pressure: Theory and model for Asian marginal seas. J. Geophys. Res., 111, C11S19, https://doi.org/ 10.1029/2005JC003189.

Sprintall, J., S. E. Wijffels, R. Molcard, and I. Jaya, 2009: Direct estimates of the Indonesian Throughflow entering the Indian Ocean: 2004-2006. J. Geophys. Res., 114, C07001, https:// doi.org/10.1029/2008JC005257.

_- A. Gordon, A. Koch-Larrouy, T. Lee, J. Potemra, K. Pujiana, and E. Wijffels, 2014: The Indonesian seas and their role in the coupled ocean-climate system. Nat. Geosci., 7, 487-492, https://doi.org/10.1038/ngeo2188.

Storch, J., C. Eden, I. Fast, H. Haak, D. Hernández-Deckers, E. Maier-Reimer, J. Marotzke, and D. Stammer, 2012: An estimate of the Lorenz energy cycle for the World Ocean based on the STORM/NCEP simulation. J. Phys. Oceanogr., 42, 2185-2205, https://doi.org/10.1175/JPO-D12-079.1.

Susanto, R. D., and A. L. Gordon, 2005: Velocity and transport of the Makassar Strait throughflow. J. Geophys. Res., 110, C01005, https://doi.org/10.1029/2004JC002425.

— , and Y. T. Song, 2015: Indonesian Throughflow proxy from satellite altimeters and gravimeters. J. Geophys. Res. Oceans, 120, 2844-2855, https://doi.org/10.1002/2014JC010382.

G. Fang, I. Soesilo, Q. Zheng, F. Qiao, Z. Wei, and B. Sulistyo, 2010: New surveys of a branch of the Indonesian Throughflow. Eos, Trans. Amer. Geophys. Union, 91, 261-263, https://doi.org/10.1029/2010EO300002.

, A. Ffield, A. Gordon, and R. Adi, 2012: Variability of Indonesian Throughflow within Makassar Strait, 2004-2009. J. Geophys. Res., 117, C09013, https://doi.org/10.1029/ 2012JC008096.
Toole, J. M., and B. A. Warren, 1993: A hydrographic section across the subtropical South Indian Ocean. Deep-Sea Res. I, 40, 1973 2019, https://doi.org/10.1016/0967-0637(93)90042-2.

Ueki, I., Y. Kashino, and Y. Kuroda, 2003: Observation of current variations off the New Guinea coast including the 1997-1998 El Niño period and their relationship with Sverdrup transport. J. Geophys. Res., 108, 3243, https://doi.org/10.1029/2002JC001611.

van Aken, H., A. van Bennekom, W. Mook, and H. Postma, 1991: Application of Munk's abyssal recipes to tracer distributions in the deep waters of the South Banda basin Oceanol. Acta, 14, 151-162, https://pdfs.semanticscholar.org/ 0154/1dddcf61affc215f34d778345f932b5959f5.pdf.

Whitehead, J. A., A. Leetmaa, and R. A. Knox, 1974: Rotating hydraulics of strait and sill flows. Geophys. Fluid Dyn., 6, 101125, https://doi.org/10.1080/03091927409365790.

Wijffels, S., and G. Meyers, 2004: Intersection of oceanic waveguides: Variability in the Indonesian Throughflow region J. Phys. Oceanogr., 34, 1232-1253, https://doi.org/10.1175/ 1520-0485(2004)034<1232:AIOOWV>2.0.CO;2.

Wunsch, C., D. Hu, and B. Grant, 1983: Mass, heat, salt and nutrient fluxes in the South Pacific Ocean. J. Phys. Oceanogr., 13, 725-753, https://doi.org/10.1175/1520-0485(1983)013<0725: MHSANF $>2.0 . \mathrm{CO} ; 2$.

Yuan, D., 2005: Role of the Kelvin and Rossby waves in the seasonal cycle of the equatorial Pacific Ocean circulation. J. Geophys. Res., 110, C04004, https://doi.org/10.1029/2004JC002344.

_ , X. Hu, P. Xu, X. Zhao, Y. Masumoto, and W. Han, 2018a: The IOD-ENSO precursory teleconnection over the tropical Indo-Pacific Ocean: Dynamics and long-term trends under global warming. J. Oceanol. Limnol., 36, 4-19, https://doi.org/ 10.1007/s00343-018-6252-4. and Coauthors, 2018b: Observed transport variations in the Maluku Channel of the Indonesian seas associated with western boundary current changes. J. Phys. Oceanogr., 48, 1803-1813, https://doi.org/10.1175/JPO-D-17-0120.1. 